\title{
The Integrated Management of Hypertension in General Hospitals and Community Hospitals
}

\author{
Kun Xie (D) \\ Xiufang Gao \\ Liwen Bao \\ Ying Shan \\ Haiming Shi \\ Yong $\mathrm{Li}$

\section{On behalf of the UPPDATE Investigators}

Cardiology Department, Huashan Hospital, Fudan University, Shanghai, People's Republic of China
Correspondence: Xiufang Gao; Yong Li Cardiology Department, Huashan Hospital, Fudan University, No. 12 Mid

Wulumuqi Road, Shanghai, 200040,

People's Republic of China

Tel +86-02I-5288706I

Email gaoxf_fudan@I26.com;

drliyong_hsh@126.com
Purpose: We sought to investigate and improve the integrated management of hypertension in general and community hospitals in China.

Patients and Methods: We carried out a cross-sectional study in 90 centers from 15 cities in China from 2017 to 2018. Patients with primary hypertension were included.

Results: Of the total 4286 patients included, $43.2 \%$ of them controlled blood pressure (BP) below $140 / 90 \mathrm{mmHg}$ while only $11.5 \%$ controlled BP below $130 / 80 \mathrm{mmHg}$. The control rate of low-density lipoprotein-C (LDL-C) in patients with concomitant coronary artery disease (CAD), diabetes (DM), and chronic kidney disease (CKD) was 24.7\%, 49.4\%, and 40.6\%, respectively. Thirty-one percent of the DM patients had HbA1c levels greater than $8 \%$ while $21.7 \%$ of the non-DM patients had $\mathrm{HbA} 1 \mathrm{c} \geq 6.5 \%$. The control rate of body mass index (BMI) was $54.4 \%$ in men and $59.8 \%$ in women. As compared to patients from community hospitals, patients from general hospitals had poorer control of $\mathrm{BP}<140 / 90 \mathrm{mmHg}$ (OR $0.63,95 \%$ CI $0.55-0.73, \mathrm{p}<0.001)$, comparatively better attainment of LDL-C, particularly $<1.8 \mathrm{mmol} / \mathrm{L}$ in CAD (OR 3.25, 95\% CI 2.02-5.24, p $<0.001$ ), similar control of HbA1c $<8.0 \%$ in diabetes (OR 0.64, 95\% CI 0.41-1.00, $\mathrm{p}=0.052$ ) and comparatively worse achievement of $\mathrm{BMI}<25 \mathrm{~kg} / \mathrm{m}^{2}$ (OR 0.72, 95\% CI 0.63-0.83, p<0.001)

Conclusion: The integrated management of hypertension needs to be improved. Besides LDL-C, the management of BP, blood glucose (BG), and BMI need to be strengthened in not only community hospitals but also general hospitals.

Keywords: hypertension, hypercholesterolemia, diabetes, body mass index, abdominal circumference

\section{Introduction}

Cardiovascular disease has been stated to be the majority of preventable mortality in non-communicable disease at the 65th World Health Assembly. ${ }^{1}$ To reduce cardiovascular morbidity and mortality, a lot of effort needs to be adopted including lifestyle management, risk factor management, and optimal medical treatment. Although there is common agreement on cardiovascular disease prevention, ${ }^{2}$ the risk assessment and management in individual patients remain insufficient. Integrated evaluation and guideline implementation should be encouraged to improve preventive cardiology.

Hypertension is highly prevalent and is the major cause of cardiovascular, cerebrovascular, and kidney disease. Therefore, lowering blood pressure (BP) will surely reduce the risks of major cardiovascular events. Unfortunately, BP control is unsatisfactory worldwide even if the target is $140 / 90 \mathrm{mmHg}$. Increasing evidence suggests that BP goes lower than $130 / 80 \mathrm{mmHg}$ will be more beneficial and modern 
guidelines focusses on lower BP targets. ${ }^{3,4}$ Thus, there will be a huge gap between guideline recommendations and the current BP management.

Additionally, metabolic disorders and other risk factors are not always taken into account by patients or specialized physicians. A large proportion of patients with hypertension are overweight, have concomitant coronary artery disease (CAD), diabetes, prediabetes, dyslipidemia, and have other risk factors like smoking. The knowledge of integrated management of hypertension is still lacking. A comprehensive management mode is critically important to further reduce the cardiovascular risks both in the primary and secondary prevention of cardiovascular disease. $^{5,6}$

A lot of effort has been previously made, but cardiovascular morbidity and mortality still rank high among the entire population. In the EUROASPIRE IV study of coronary patients from 78 centers in 24 European countries, $42.7 \%$ had blood pressure (BP) $\geq 140 / 90 \mathrm{mmHg}, 80.5 \%$ had low-density lipoprotein cholesterol (LDL-C) $\geq 1.8 \mathrm{mmol} / \mathrm{l}$, $26.8 \%$ had self-reported diabetes and $37.6 \%$ had body mass index (BMI) $\geq 30 \mathrm{~kg} / \mathrm{m}^{2}{ }^{7}$ Not only in secondary prevention but also in primary prevention, there is still a lot that can be done to narrow the gap between the guidelines and the current undertreatment of hypertensive patients.

Concerning integrated management of hypertension for primary and secondary prevention, general hospitals and community hospitals should both be involved. To investigate the current management of hypertension in China and the roles that general hospitals and community hospitals play in this field, we carried out a national observational study to illustrate the integrated management in hypertension. We aimed to identify the main differences between general and community hospitals and to improve the preventive cardiology in both settings.

\section{Patients and Methods}

We carried out a cross-sectional study (UPPDATE STUDY) in 90 centers from 15 cities in China from 2017 to 2018. Patients with primary hypertension were recruited from the out-patient clinics using convenience sampling in both general hospitals and community hospitals. The inclusion criteria were patients with primary hypertension who were older than 18 years old. The exclusion criteria were patients with secondary hypertension, active tumor, or cognitive impairment. Information was collected with a detailed questionnaire for each participant.
All participants provided written informed consent and approved the information to be published. Research protocols were approved by the Ethics Committee of Huashan Hospital, Fudan University (2017-282-1). The study was conducted in accordance with the Declaration of Helsinki. The patient and public were involved to provide patientcentered healthcare services.

Office BP was measured three times with one-minute interval at each visit and the average of the last two readings was recorded. The targets were defined as office $\mathrm{BP}<$ $140 / 90 \mathrm{mmHg}$ or office $\mathrm{BP}<130 / 80 \mathrm{mmHg}$ according to the guidelines. LDL-C targets were defined according to the 2016 Chinese guideline of dyslipidemia as $<1.8 \mathrm{mmol} /$ $\mathrm{L}$ for very high risk, $<2.6 \mathrm{mmol} / \mathrm{L}$ for high risk, and $<3.4$ $\mathrm{mmol} / \mathrm{L}$ for mid and low risk. The targets of glycemic control were defined according to 2019 ADA guidelines of diabetes as $<6.5 \%$ (more stringent), $<7.0 \%$ (reasonable), and $<8.0 \%$ (less stringent). ${ }^{8} \mathrm{CKD}$ was defined as estimated glomerular filtration rate $(\mathrm{eGFR})<60 \mathrm{~mL} / \mathrm{min} / 1.73 \mathrm{~m}^{2}$ (MDRD Equation). Overweight was defined as $25 \mathrm{~kg} / \mathrm{m}^{2}$ $\leq \mathrm{BMI}<30 \mathrm{~kg} / \mathrm{m}^{2}$ and obesity was defined as BMI $\geq 30 \mathrm{~kg} /$ $\mathrm{m}^{2}$ according to the $2000 \mathrm{WHO}$ standard. ${ }^{9}$ Elevated waist circumference was defined according to the 2005 AHA guideline as greater than $90 \mathrm{~cm}$ in males and greater than $80 \mathrm{~cm}$ in females (Asian). ${ }^{10}$

Student's $t$-test was used for continuous variables and Chi-square test was used for categorical variables. Logistic regression was used to compare the control rate in general hospitals and community hospitals. A forward stepwise method was used in the logistic regression model. Odds ratios (OR) and 95\% confidence intervals were used for the estimation. $\mathrm{P}<0.05$ was considered statistically significant. Stata 13.0 was used for statistical analysis.

\section{Results General Characteristics}

A total of 4286 participants were included (Figure 1). Among them, 56\% were male. The average age was $64.81 \pm 12.71$ years. $92.5 \%$ of them were on antihypertensive therapy and had an average BP of $141.65 \pm 17.35 /$ $83.45 \pm 11.88 \mathrm{mmHg}$. The average BMI was 24.88 $\pm 4.04 \mathrm{~kg} / \mathrm{m}^{2}$. The Smoking rate was $14.3 \%$ in total participants and $24.3 \%$ in males. $54.8 \%$ of participants were receiving statin therapy. $22.4 \%$ of them had diabetes and $20.6 \%$ had CAD. $22.0 \%$ of the participants had CKD and the average eGFR was $79.24 \pm 29.18$ (Table 1). 


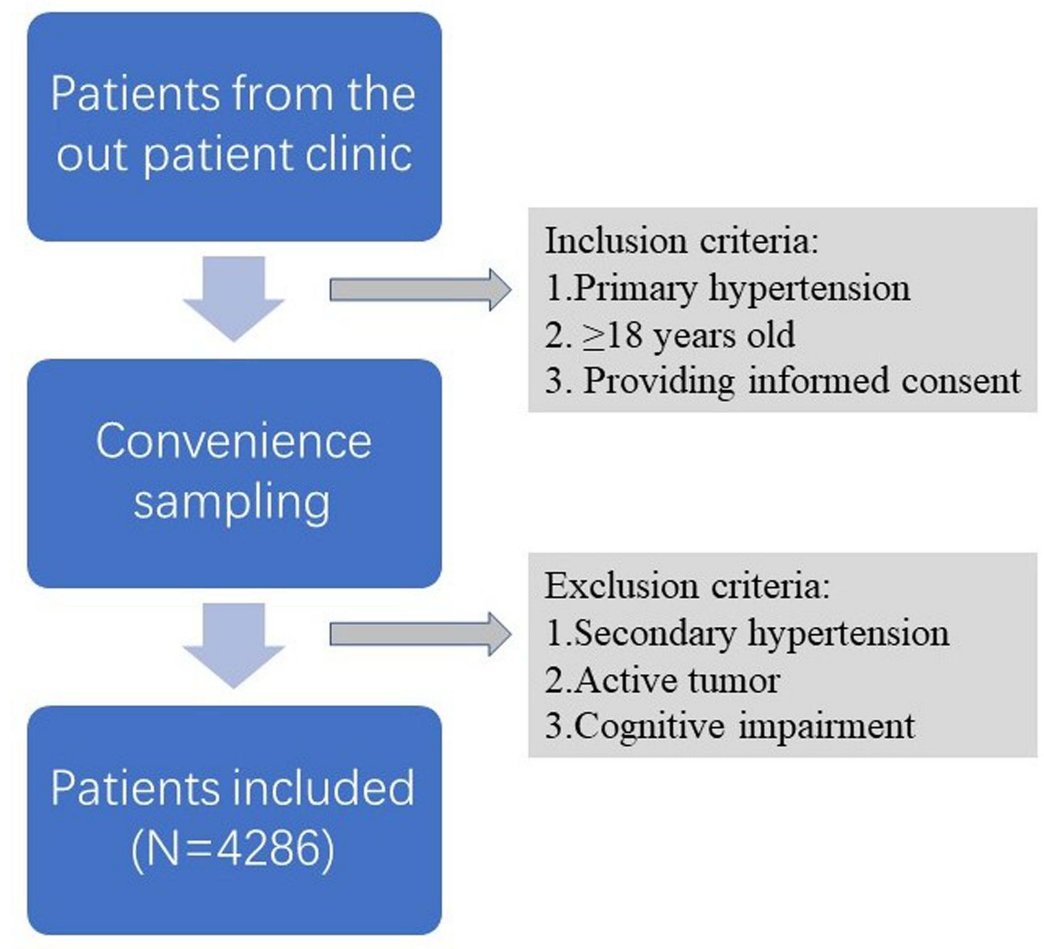

Figure I The flow charts of the inclusion/exclusion steps of the cross-sectional study.

\section{The Integrated Management of Hypertension}

In patients with hypertension, $92.5 \%$ were on antihypertensive medication. Only $43.2 \%$ achieved BP $<140 / 90 \mathrm{mmHg}$ and $11.5 \%$ achieved $\mathrm{BP}<130 / 80 \mathrm{mmHg}$. The proportion of patients with $\mathrm{BP}<140 / 90 \mathrm{mmHg}$ ranged from $18.2 \%$ to $47.5 \%$ according to the age groups. Patients in their 20 's had the lowest control rate of $18.2 \%$ and patients in their 60 's had the highest control rate of $47.5 \%$. The proportion of patients with $\mathrm{BP}<130 / 80 \mathrm{mmHg}$ ranged from $0 \%$ to $15.7 \%$ according to the age groups. The control of BP was poor particularly in young patients (Figure 2).

According to the 2016 Chinese Guideline of Dyslipidemia, patients with LDL-C lower than $1.8 \mathrm{mmol} /$ $\mathrm{L}$ accounted for $14.2 \%, 1.8-2.6 \mathrm{mmol} / \mathrm{L}$ accounted for $29.3 \%$ and $2.6-3.4 \mathrm{mmol} / \mathrm{L}$ accounted for $30.1 \%$. 26.4\% of the patients did not achieve the LDL-C target of 3.4 $\mathrm{mmol} / \mathrm{L}(\geq 3.4 \mathrm{mmol} / \mathrm{L})$ (Figure 1$)$.

CAD accounted for $20.5 \%$ of the participants. But only $24.7 \%$ of patients with CAD achieved the target of LDL-C $<1.8 \mathrm{mmol} / \mathrm{L}$. Diabetes accounted for $22.3 \%$ of the participants. $50.5 \%$ of patients with diabetes did not achieve the target of LDL-C $<2.6 \mathrm{mmol} / \mathrm{L}$. CKD accounted for $22.0 \%$ of the participants. $59.5 \%$ of patients with CKD did not achieve the target of LDL-C $<2.6 \mathrm{mmol} / \mathrm{L}$ Unfortunately, smoking rates did not decrease in hypertension with $\mathrm{CAD}$, diabetes, or $\mathrm{CKD}$. BMI value did not decrease either. Hypertensive patients with diabetes and CKD had increased BMI values (Table 2).

$22.3 \%$ of the total patients had self-reported diabetes. BG was poorly controlled. HbA1c levels greater than $8.0 \%$ reached $31 \%$ in patients with diabetes. In patients without self-reported diabetes, $40.5 \%$ of them had FBG in the range of $5.6-7.0 \mathrm{mmol} / \mathrm{L}$ and $21.8 \%$ of them had $\mathrm{HbA} 1 \mathrm{c}$ greater than $6.5 \%$, which met the diagnosis of pre-diabetes and diabetes. ${ }^{11}$ (Table 3)

The average BMI was $24.68 \pm 4.40$ in females and 25.05 \pm 3.72 in males. $59.8 \%$ of the females and $54.4 \%$ of the males attained the BMI targets. The average abdominal circumference was $82.28 \pm 13.34 \mathrm{~cm}$ in females and $87.96 \pm 14.31 \mathrm{~cm}$ in males. Only $38.7 \%$ of the female and $57.9 \%$ of the males achieved the target of the abdominal circumference (Table 4).

\section{Characteristics of Patients from General and Community Hospitals}

Patients of general hospitals were much younger than those of community hospitals $(63.0 \pm 13.3$ vs $67.0 \pm 12.3$, $\mathrm{p}<0.01)$. Males accounted for more in general hospitals than in community hospitals $(61.8 \%$ vs $53.6 \%, \mathrm{p}<0.01)$. 
Table I General Characteristics of Patients with Hypertension

\begin{tabular}{|c|c|c|c|c|}
\hline & Total $\mathrm{N}=4286$ & Female $\mathbf{N}=\mid \mathbf{8 8 5}$ & Male $\mathbf{N}=\mathbf{2 4 0} \mathrm{I}$ & $\mathbf{p}$ \\
\hline Age & $64.81 \pm|2.7|$ & $65.87 \pm 11.59$ & $63.98 \pm 13.46$ & $<0.001$ \\
\hline BMI & $24.88 \pm 4.04$ & $24.68 \pm 4.40$ & $25.05 \pm 3.72$ & 0.003 \\
\hline Abdominal circumference $(\mathrm{cm})$ & $85.45 \pm 14.17$ & $82.28 \pm 13.34$ & $87.96 \pm|4.3|$ & $<0.001$ \\
\hline Smoking & $14.3 \%$ & $1.6 \%$ & $24.3 \%$ & $<0.001$ \\
\hline SBP $(\mathrm{mmHg})$ & $141.65 \pm 17.35$ & $14 \mid .44 \pm 17.70$ & $|4| .8 \mid \pm 17.08$ & 0.49 \\
\hline $\mathrm{DBP}(\mathrm{mmHg})$ & $83.45 \pm 11.88$ & $82.46 \pm \mid 1.71$ & $84.23 \pm 11.95$ & $<0.001$ \\
\hline $\mathrm{BP}<140 / 90 \mathrm{mmHg}(\%)$ & $43.2 \%$ & $45.3 \%$ & $41.6 \%$ & 0.018 \\
\hline $\mathrm{BP}<130 / 80 \mathrm{mmHg}(\%)$ & $11.5 \%$ & $13.5 \%$ & $10.0 \%$ & $<0.001$ \\
\hline Antihypertensive therapy & $92.5 \%$ & $94.0 \%$ & $91.4 \%$ & $<0.001$ \\
\hline $\mathrm{TC}(\mathrm{mmol} / \mathrm{L})$ & $4.79 \pm 1.33$ & $4.99 \pm 1.31$ & $4.63 \pm 1.31$ & $<0.001$ \\
\hline LDL-C (mmol/L) & $2.84 \pm 1.13$ & $2.98 \pm 1.27$ & $2.72 \pm 0.97$ & $<0.001$ \\
\hline $\mathrm{HDL}-\mathrm{C}(\mathrm{mmol} / \mathrm{L})$ & $1.27 \pm 0.33$ & $1.34 \pm 0.32$ & $1.21 \pm 0.32$ & $<0.001$ \\
\hline $\mathrm{TG}(\mathrm{mmol} / \mathrm{L})$ & $2.02 \pm 1.54$ & $2.05 \pm 1.49$ & $1.99 \pm 1.58$ & 0.32 \\
\hline Statin treatment & $54.8 \%$ & $56.3 \%$ & $53.5 \%$ & 0.09 \\
\hline DM & $22.4 \%$ & $22.3 \%$ & $22.4 \%$ & 0.96 \\
\hline CAD & $20.6 \%$ & $21.0 \%$ & $20.3 \%$ & 0.61 \\
\hline CKD & $22.0 \%$ & $25.5 \%$ & $19.3 \%$ & $<0.001$ \\
\hline eGFR & $79.24 \pm 29.18$ & $75.13 \pm 26.92$ & $82.48 \pm 30.47$ & $<0.001$ \\
\hline
\end{tabular}

Abbreviations: BMI, body mass index; SBP, systolic blood pressure; DBP, diastolic blood pressure; TC, total cholesterol; LDL-C, low density lipoprotein-C; HDL-C, high density lipoprotein-C; TG, triglyceride; DM, diabetes mellitus; eGFR, estimated glomerular filtration rate.

The average BP in general hospitals was higher than that in community hospitals $(144.6 \pm 20.5 / 85.6 \pm 13.6 \mathrm{mmHg}$ vs $140.0 \pm 16.4 / 82.9 \pm 11.9 \mathrm{mmHg}, \mathrm{p}<0.01)$. Fewer patients had their BP controlled under $140 / 90 \mathrm{mmHg}$ in general hospitals than in community hospitals $(34.5 \%$ vs $46.6 \%$, $\mathrm{p}<0.01$ ). ABPM was not frequently used in general or community hospitals $(4.2 \%$ vs $4.9 \%, \mathrm{p}=0.34)$.

The plasma lipid levels were much more wellcontrolled in general hospitals than in community hospitals. In patients with CAD, more patients achieved LDL-C lower than $1.8 \mathrm{mmol} / \mathrm{L}$ in general hospitals than in community hospitals $(39.7 \%$ vs $16.7 \%, \mathrm{p}<0.01)$.

However, blood glucose was still poorly managed and the average $\mathrm{HbAlc}$ was higher in general hospitals than in community hospitals $(8.2 \pm 2.5$ vs $7.4 \pm 1.9, \mathrm{p}<0.01)$.

The average BMI was also higher in general hospitals than in community hospitals $(25.3 \pm 3.7$ vs $24.7 \pm 4.2$, $\mathrm{p}<0.01$ ) (Table 5).
After adjusting for age, gender, anti-hypertensive therapy, statin therapy, and anti-diabetes therapy, general hospitals turned out to have worse control of $\mathrm{BP}<140$ / $90 \mathrm{mmHg}$ (OR 0.63, 95\% CI 0.55-0.73, p<0.001) and similar control of $\mathrm{BP}<130 / 80 \mathrm{mmHg}$ (OR $0.85,95 \% \mathrm{CI}$ $0.68-1.06, \mathrm{p}=0.138$ ), comparing to community hospitals (Table 6).

Patients in general hospitals had better control of LDL$\mathrm{C}<1.8 \mathrm{mmol} / \mathrm{L}$ in CAD (OR 3.25, 95\% CI 2.02-5.24, $\mathrm{p}<0.001$ ), better control of LDL-C $<2.6 \mathrm{mmol} / \mathrm{L}$ in $\mathrm{DM}$ (OR 1.57, 95\% CI 1.05-2.34, $\mathrm{p}=0.026$ ) and better control of LDL-C $<2.6 \mathrm{mmol} / \mathrm{L}$ in CKD (OR 3.13, 95\% CI 1.72-5.71, p<0.001) (Table 6).

The control of HbAlc in patients with DM was similar in general and community hospitals at the target of $6.5 \%$ (OR $0.77,95 \%$ CI $0.47-1.25, p=0.292$ ), the goal of $<7.0 \%$ (OR 0.83, 95\% CI 0.54-1.27, $\mathrm{p}=0.393$ ) and the target of $8 \%$ (OR 0.64, 95\% CI 0.41-1.00, $\mathrm{p}=0.052$ ) (Table 6). 


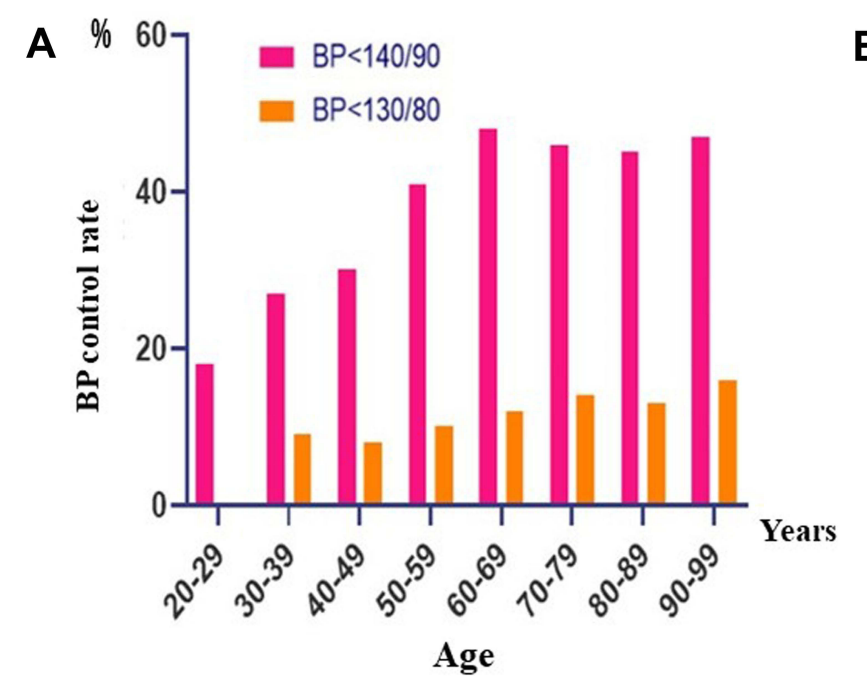

\section{B}

\section{LDL-C achievement}
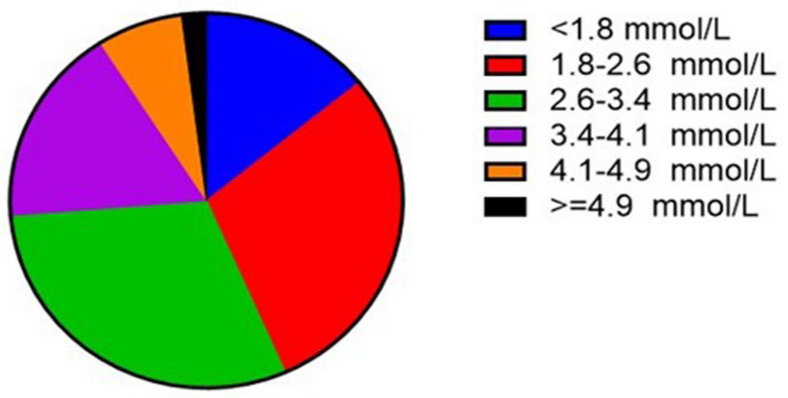

Figure 2 The control of BP and LDL-C in patients with hypertension. (A) The control rate of $\mathrm{BP}<140 / 90 \mathrm{mmHg}$ and $\mathrm{BP}<130 / 80 \mathrm{mmHg}$ according to the age categories. (B) The control of LDL-C in hypertensive patients.

Abbreviations: BP, blood pressure; LDL-C, low-density lipoprotein cholesterol.

The control of BMI was worse in general hospitals comparing to community hospitals (OR $0.72,95 \%$ CI 0 .63-0.83, $\mathrm{p}<0.001$ ) (Table 6).

\section{Discussion}

Our study illustrated the inadequate integrated management of BP and other risk factors in patients with hypertension. Although $92.5 \%$ of hypertension were on antihypertensive treatment, only $43.2 \%$ of them controlled BP below 140/90 mmHg and 11.5\% controlled BP below 130/90 mmHg. BP control in younger patients was poorer than average. Approximately half of the patients were taking statins, but LDL-C control was around $24.7-49.4 \%$ in very high-risk and high-risk patients. In patients with self-reported diabetes, $31 \%$ had HbA1c greater than $8.0 \%$. In patients without self-reported diabetes, $40.5 \%$ had impaired fasting glucose and $21.8 \%$ had $\mathrm{HbAlc}$ greater than $6.5 \%$. BMI control was around 54.4\%-59.8\%. Waist circumference was particularly poorly managed in females. Smoking rate was $14.3 \%$ in total and $24.3 \%$ in males, which did not tend to decrease in patients with concomitant CAD, diabetes, and CKD.

Compared to the community hospitals, the general hospitals achieved much lower LDL-C levels in very high-

Table 2 LDL-C Management in Patients with Concomitant CAD, Diabetes and CKD

\begin{tabular}{|c|c|c|c|c|c|c|c|c|c|}
\hline & Non-CAD & CAD & $\mathbf{p}$ & Non-Diabetes & Diabetes & $\mathbf{p}$ & Non-CKD & CKD & $\mathbf{p}$ \\
\hline Smoking & $14.6 \%$ & $13.1 \%$ & 0.28 & $13.8 \%$ & $16.3 \%$ & 0.07 & $13.1 \%$ & $13.2 \%$ & 0.83 \\
\hline BMI & $24.88 \pm 3.95$ & $24.88 \pm 3.68$ & 0.99 & $24.78 \pm 3.81$ & $25.20 \pm 4.11$ & 0.005 & $24.91 \pm 3.87$ & $25.6 I \pm 5.97$ & 0.001 \\
\hline Statin(\%) & $47.4 \%$ & $79.8 \%$ & $<0.001$ & $50.7 \%$ & $66.2 \%$ & $<0.001$ & $58.2 \%$ & $67.1 \%$ & $<0.001$ \\
\hline LDL-C (mmol/L) & & & $<0.001$ & & & 0.04 & & & $<0.001$ \\
\hline$<1.8$ & $11.1 \%$ & $24.7 \%$ & & $13.1 \%$ & $17.5 \%$ & & $15.9 \%$ & $12.9 \%$ & \\
\hline $1.8-2.6$ & $28.9 \%$ & $33.4 \%$ & & $29.0 \%$ & $31.9 \%$ & & $32.5 \%$ & $27.7 \%$ & \\
\hline $2.6-3.4$ & $32.7 \%$ & $21.4 \%$ & & $30.7 \%$ & $29.1 \%$ & & $29.3 \%$ & $29.4 \%$ & \\
\hline $3.4-4.1$ & $16.9 \%$ & $13.4 \%$ & & $17.0 \%$ & $13.2 \%$ & & $14.7 \%$ & $18.2 \%$ & \\
\hline 4.1-4.9 & $8.0 \%$ & $5.8 \%$ & & $7.8 \%$ & $6.3 \%$ & & $6.5 \%$ & $7.6 \%$ & \\
\hline$\geq 4.9$ & $2.4 \%$ & $1.3 \%$ & & $2.4 \%$ & $1.9 \%$ & & $1.2 \%$ & $4.3 \%$ & \\
\hline
\end{tabular}

Abbreviations: CAD, coronary artery disease; CKD, chronic kidney disease; LDL-C, low density lipoprotein-C. 
Table 3 BG Management in Patients with Hypertension

\begin{tabular}{|c|c|c|c|}
\hline & Non-Diabetes & Diabetes & $\mathbf{P}$ \\
\hline FBG $(\mathrm{mmol} / \mathrm{L})$ & & & $<0.00 \mathrm{I}$ \\
\hline$<5.6$ & $54.1 \%$ & $11.4 \%$ & \\
\hline $5.6-7.0$ & $40.5 \%$ & $32.4 \%$ & \\
\hline$\geq 7.0$ & $5.4 \%$ & $56.2 \%$ & \\
\hline HbAIc (\%) & & & $<0.001$ \\
\hline$<6.5$ & $78.3 \%$ & $26.2 \%$ & \\
\hline $6.5-7.0$ & $12.1 \%$ & $17.5 \%$ & \\
\hline $7.0-8.0$ & $2.7 \%$ & $25.3 \%$ & \\
\hline$\geq 8.0$ & $7.0 \%$ & $31.0 \%$ & \\
\hline
\end{tabular}

Abbreviation: FBG, fasting blood glucose.

Table 4 Body Weight Management in Patients with Hypertension

\begin{tabular}{|l|l|l|l|l|}
\hline & Total & Female & Male & $\mathbf{p}$ \\
\hline BMI $\left(\mathrm{kg} / \mathrm{m}^{2}\right)$ & $24.88 \pm 4.04$ & $24.68 \pm 4.40$ & $25.05 \pm 3.72$ & 0.003 \\
\hline BMI & & & & $<0.001$ \\
\hline BMI $<25\left(\mathrm{~kg} / \mathrm{m}^{2}\right)$ & $56.8 \%$ & $59.8 \%$ & $54.4 \%$ & \\
\hline $\begin{array}{l}\text { BMI } 25-30(\mathrm{~kg} / \\
\left.\mathrm{m}^{2}\right)\end{array}$ & $36.8 \%$ & $33.5 \%$ & $39.4 \%$ & \\
\hline \multicolumn{1}{|c|}{ BMI $\geq 30\left(\mathrm{~kg} / \mathrm{m}^{2}\right)$} & $6.4 \%$ & $6.7 \%$ & $6.2 \%$ & \\
\hline $\begin{array}{l}\text { Abdominal } \\
\text { circumference }(\mathrm{cm})\end{array}$ & $85.45 \pm 14.17$ & $82.28 \pm 13.34$ & $87.96 \pm 14.31$ & $<0.001$ \\
\hline $\begin{array}{l}\text { Abdominal } \\
\text { circumference } \\
\text { controlled \% }\end{array}$ & 1 & $38.7 \%$ & $57.9 \%$ & $<0.001$ \\
\hline
\end{tabular}

Abbreviation: BMI, body mass index.

risk and high-risk patients. However, the control of BP and BMI were worse in general hospitals while the control of $\mathrm{HbAlc}$ was similar in the two settings of hospitals.

Besides LDL-C, the management of BP, BG, and BMI should also be strengthened not only in community hospitals but also in general hospitals. The achievement in general hospitals was not superior as expected. Three possible reasons were considered. The first being that patients in general hospitals might be more seriously ill, usually having more comorbidities. The second reason being that patients were treated in a more specialized model in general hospitals rather than an interdisciplinary model in community hospitals. The last reason that was considered was that LDL-C lowering therapy had always been emphasized over other risk factors particularly in cardiologists from general hospitals.
The integrated management of BP and other risk factors has been demonstrated to be critically important to improve the prognosis of hypertensive patients. BP, BG, lipid, weight, and lifestyle management are the integrated strategies that will reduce the risk of cardiovascular disease far more than BP management alone.

The SPRINT study showed that intensive treatment of systolic blood pressure (SBP) lower than $120 \mathrm{mmHg}$ could significantly reduce the primary outcome compared to the standard treatment $(\mathrm{SBP}<140 \mathrm{mmHg})$ in patients with hypertension. ${ }^{12}$ The 2017 ACC guidelines have already lowered the definition of hypertension and BP target from 140/90 mmHg to $130 / 80 \mathrm{mmHg}$. ${ }^{4}$ The 2018 ESC guidelines have defined 130-139/85-89 mmHg as high normal and treated BP should be targeted to $<130 / 80 \mathrm{mmHg}$ if tolerated. ${ }^{3}$ The recently published 2020 ISH guidelines also defined 130-139/85-89 mmHg as high normal, the essential target should be $140 / 90 \mathrm{mmHg}$ and the optimal target should be $130 / 80 \mathrm{mmHg}$ in patients $<65$ years. ${ }^{13}$

Similarly, the 2019 ESC guidelines for the management of dyslipidemia have lowered the target of LDL-C level from $1.8 \mathrm{mmol} / \mathrm{L}$ to $1.4 \mathrm{mmol} / \mathrm{L}$ in patients with very high risks. ${ }^{14}$ The gap between the guideline implementation and the clinical practice seems to be widening rather than narrowing.

The prevalence of diabetes has always been increasing due to population growth, aging, economic development, and lifestyle change. The worldwide prevalence of diabetes increased from $4.3-5.0 \%$ to $7.9-9.0 \%$ from 1980 to $2014 .{ }^{15}$ In China, the prevalence of diabetes increased from $9.7 \%$ in 2007 to $10.4 \%$ in 2013 and $11.2 \%$ in 2017 and the prevalence of prediabetes was $35.7 \%$ in $2013 .{ }^{16-18}$ In our study, the prevalence of diabetes was $22.3 \%$ in hypertensive patients. In the recently published 2019 ESC guidelines on diabetes, prediabetes and cardiovascular disease, the management of BG in cardiovascular disease has been highlighted which indicated the brand-new concept of preventive cardiology. ${ }^{19}$ The ISH guidelines have also recommended FBG $<7 \mathrm{mmol} / 1$ or $\mathrm{HbA} 1 \mathrm{c}<7 \%$ in hypertension. ${ }^{13} \mathrm{~A}$ lot of effort is required in the integrated management to improve the primary and secondary prevention of cardiovascular diseases.

The prevalence of obesity has also been rising in the past ten years from $5.7 \%$ to $6.3 \% .{ }^{17}$ In our study, obese patients accounted for $6.4 \%$ whereas overweight patients accounted for $36.8 \%$, which remained as a large population to be managed to achieve further fitness. The prevalence of obesity $\left(\mathrm{BMI} \geq 30 \mathrm{~kg} / \mathrm{m}^{2}\right.$ ) and central obesity (waist circumferen$\mathrm{ce} \geq 80 \mathrm{~cm}$ ) was found to be higher in females. 
Table 5 Integrated Management of Hypertension in General and Community Hospitals

\begin{tabular}{|c|c|c|c|}
\hline & Community Hospitals & General Hospitals & $\mathbf{p}$ \\
\hline Total number & 3039 & 1247 & \\
\hline Age (years) & $67.0 \pm 12.3$ & $63.0 \pm 13.3$ & $<0.001$ \\
\hline Male & $53.6 \%$ & $61.8 \%$ & $<0.001$ \\
\hline CAD & $19.8 \%$ & $22.5 \%$ & 0.06 \\
\hline DM & $21.8 \%$ & $23.7 \%$ & 0.81 \\
\hline CKD & $14.1 \%$ & $9.4 \%$ & $<0.001$ \\
\hline Antihypertensive therapy (\%) & $92.8 \%$ & $91.8 \%$ & 0.23 \\
\hline $\mathrm{SBP}(\mathrm{mmHg})$ & $140.0 \pm 16.4$ & $144.6 \pm 20.5$ & $<0.001$ \\
\hline $\mathrm{DBP}(\mathrm{mmHg})$ & $82.9 \pm 11.9$ & $85.6 \pm 13.6$ & $<0.001$ \\
\hline $\mathrm{BP}<140 / 90 \mathrm{mmHg}$ & $46.6 \%$ & $34.5 \%$ & $<0.001$ \\
\hline $\mathrm{BP}<130 / 90 \mathrm{mmHg}$ & $12.2 \%$ & $10.0 \%$ & 0.04 \\
\hline ABPM \% & $4.9 \%$ & $4.2 \%$ & 0.34 \\
\hline $\mathrm{TC}(\mathrm{mmol} / \mathrm{L})$ & $4.91 \pm 1.33$ & $4.51 \pm 1.26$ & $<0.001$ \\
\hline $\mathrm{HDL}-\mathrm{C}(\mathrm{mmol} / \mathrm{L})$ & $1.32 \pm 0.33$ & $1.16 \pm 0.29$ & $<0.001$ \\
\hline TG (mmol/L) & $2.07 \pm 1.57$ & $1.90 \pm 1.45$ & 0.02 \\
\hline LDL-C (mmol/L) & $2.92 \pm 1.18$ & $2.64 \pm 0.97$ & $<0.001$ \\
\hline LDL-C in CAD & & & $<0.001$ \\
\hline$<1.8$ & $16.7 \%$ & $39.7 \%$ & \\
\hline $1.8-2.6$ & $33.4 \%$ & $33.3 \%$ & \\
\hline $2.6-3.4$ & $25.3 \%$ & $14.1 \%$ & \\
\hline$\geq 3.4$ & $24.6 \%$ & $12.8 \%$ & \\
\hline LDL-C in Non-CAD & & & 0.06 \\
\hline$<1.8$ & $10.2 \%$ & $13.4 \%$ & \\
\hline $1.8-2.6$ & $27.7 \%$ & $32.0 \%$ & \\
\hline $2.6-3.4$ & $34.1 \%$ & $29.0 \%$ & \\
\hline$\geq 3.4$ & $28.0 \%$ & $25.6 \%$ & \\
\hline \multicolumn{4}{|l|}{ Diabetes } \\
\hline $\mathrm{FBG}(\mathrm{mmol} / \mathrm{L})$ & $7.6 \pm 2.6$ & $8.1 \pm 2.9$ & 0.039 \\
\hline $\mathrm{HbAlc}(\%)$ & $7.4 \pm 1.9$ & $8.2 \pm 2.5$ & $<0.001$ \\
\hline Anti-diabetes medication (\%) & $89.2 \%$ & $85.8 \%$ & 0.16 \\
\hline \multicolumn{4}{|l|}{ Non-diabetes } \\
\hline $\mathrm{FBG}(\mathrm{mmol} / \mathrm{L})$ & $5.6 \pm 0.9$ & $5.7 \pm 1.2$ & 0.07 \\
\hline HbAlc (\%) & $6.2 \pm 1.6$ & $6.2 \pm 1.8$ & 0.86 \\
\hline BMI & $24.7 \pm 4.2$ & $25.3 \pm 3.7$ & $<0.001$ \\
\hline
\end{tabular}

Abbreviations: CAD, coronary artery disease; DM, diabetes mellitus; CKD, chronic kidney disease; SBP, systolic blood pressure; DBP, diastolic blood pressure; ABPM, arterial blood pressure monitoring; TC, total cholesterol; LDL-C, low density lipoprotein-C; HDL-C, high density lipoprotein-C; TG, triglyceride; FBG, fasting blood glucose; BMI, body mass index. 
Table 6 The Achievement of BP, LDL-C, HbAlc and BMI in General Hospitals Compared to Those in Community Hospitals

\begin{tabular}{|c|c|c|c|c|c|c|}
\hline & Model I & & Model 2 & & Model 3 & \\
\hline & OR $(95 \% \mathrm{Cl})$ & $\mathbf{p}$ & OR $(95 \% \mathrm{Cl})$ & $\mathbf{p}$ & OR $(95 \% \mathrm{Cl})$ & $\mathbf{p}$ \\
\hline \multicolumn{7}{|l|}{$\mathrm{BP}(\mathrm{mmHg})$} \\
\hline$<140 / 90$ & $0.60(0.52-0.69)$ & $<0.001$ & $0.63(0.55-0.73)$ & $<0.001$ & $0.63(0.55-0.73)$ & $<0.001$ \\
\hline$<130 / 80$ & $0.80(0.64-0.99)$ & 0.044 & $0.86(0.69-1.07)$ & 0.182 & $0.85(0.68-1.06)$ & 0.138 \\
\hline \multicolumn{7}{|l|}{ LDL-C (mmol/L) } \\
\hline$<1.8$ in CAD & $3.28(2.11-5.12)$ & $<0.001$ & $3.42(2.13-5.48)$ & $<0.001$ & $3.25(2.02-5.24)$ & $<0.001$ \\
\hline$<2.6$ in DM & $1.4(0.97-2.04)$ & 0.076 & $1.57(1.06-2.33)$ & 0.024 & $1.57(1.05-2.34)$ & 0.026 \\
\hline$<2.6$ in CKD & $3.05(1.71-5.46)$ & $<0.001$ & $3.04(1.67-5.52)$ & $<0.001$ & $3.13(1.72-5.7 \mid)$ & $<0.001$ \\
\hline \multicolumn{7}{|l|}{ HbAlc (\%) } \\
\hline$<6.5$ in DM & $0.81(0.51-1.30)$ & 0.392 & $0.82(0.50-1.32)$ & 0.405 & $0.77(0.47-1.25)$ & 0.292 \\
\hline$<7.0$ in DM & $0.82(0.55-1.24)$ & 0.359 & $0.85(0.56-1.29)$ & 0.437 & $0.83(0.54-1.27)$ & 0.393 \\
\hline$<8.0$ in DM & $0.59(0.39-0.91)$ & 0.016 & $0.63(0.4 I-0.97)$ & 0.037 & $0.64(0.41-1.00)$ & 0.052 \\
\hline \multicolumn{7}{|l|}{ BMI (kg/m2) } \\
\hline$<25$ & $0.65(0.57-0.74)$ & $<0.001$ & $0.70(0.61-0.80)$ & $<0.001$ & $0.72(0.63-0.83)$ & $<0.001$ \\
\hline
\end{tabular}

Notes: Model I: unadjusted OR; Model 2: OR adjusted for gender and age; Model 3: OR adjusted for gender, age, anti-hypertensive therapy, statin therapy, antihyperglycemia therapy.

Abbreviations: BP, blood pressure; LDL-C, low density lipoprotein-C; CAD, coronary artery disease; DM, diabetes mellitus; CKD, chronic kidney disease; BMI, body mass index.

There are several ways to improve the integrated management of hypertension. Great effort should be made to follow up with the patients to optimize the medical therapy. The guidelines should be implemented during daily clinical practice for better achievement of the targets. Patients should be screened and risk assessment should be done for better evaluation in primary and secondary prevention. The knowledge of lifestyle management should be further strengthened during patient education. On the other side, patients should be treated as a whole rather than from a single aspect. The integrated management and whole disease course management of hypertension should be adopted in not only community hospitals but also general hospitals.

The weakness of our study was the relatively small sample size. Moreover, patients were recruited using convenience sampling which could have caused bias. However, the strength of our study was that it was a multi-center cross-sectional study with 15 cities all over the country which made it possible for the results to be generalized to all patients in China. Furthermore, to our knowledge, it was the first study to compare the integrated management and guidelines implementation in general and community hospitals. More effort should be made in not only community hospitals but also general hospitals to reduce cardiovascular morbidity and mortality.

\section{Conclusions}

There was a huge gap between guideline implementation and clinical practice concerning the integrated management of hypertensive patients. A lot more effort is required in both general and community hospitals to reduce the risk of cardiovascular diseases in patients with hypertension.

\section{Data Sharing Statement}

The datasets are available from the corresponding author on reasonable request.

\section{Ethics Approval and Informed Consent}

The research protocols were approved by the Ethics Committee of Huashan Hospital, Fudan University (2017-282-1). All participants provided written informed consent and approved the information to be published.

\section{Consent for Publication}

Consent for publication has been provided by patients.

\section{Author Contributions}

All authors made a significant contribution to the work reported, whether that is in the conception, study design, 
execution, acquisition of data, analysis and interpretation, or in all these areas; took part in drafting, revising or critically reviewing the article; gave final approval of the version to be published; have agreed on the journal to which the article has been submitted; and agree to be accountable for all aspects of the work.

\section{Funding}

This work was supported by the Shanghai Health Committee (grant number ZY (2018-2020)-ZWB-1001CPJS16).

\section{Disclosure}

The authors declare that there is no conflict of interest.

\section{References}

1. World Health Organization. 65th World Health Assembly closes with new global health measures. Cent Eur J Public Health. 2012;20(2):163-164.

2. Authors/Task Force M, Piepoli MF, Hoes AW, Agewall S, et al. 2016 European guidelines on cardiovascular disease prevention in clinical practice: the sixth joint task force of the European Society of Cardiology and other societies on cardiovascular disease prevention in clinical practice (constituted by representatives of 10 societies and by invited experts): developed with the special contribution of the European Association for Cardiovascular Prevention \& Rehabilitation (EACPR). Eur J Prev Cardiol. 2016;23(11):NP1NP96. doi:10.1177/2047487316653709

3. Williams B, Mancia G, Spiering W, et al. 2018 ESC/ESH guidelines for the management of arterial hypertension. Eur Heart J. 2018;39 (33):3021-3104.

4. Whelton PK, Carey RM, Aronow WS, et al. 2017 ACC/AHA/AAPA/ $\mathrm{ABC} / \mathrm{ACPM} / \mathrm{AGS} / \mathrm{APhA} / \mathrm{ASH} / \mathrm{ASPC} / \mathrm{NMA} / \mathrm{PCNA}$ guideline for the prevention, detection, evaluation, and management of high blood pressure in adults: executive summary: a report of the American College of Cardiology/American Heart Association task force on clinical practice guidelines. Hypertension. 2018;71(6):1269-1324. doi:10.1161/HYP.0000000000000066

5. Kotseva K, De Backer G, De Bacquer D, et al. Lifestyle and impact on cardiovascular risk factor control in coronary patients across 27 countries: results from the European Society of Cardiology ESC-EORP EUROASPIRE V registry. Eur J Prev Cardiol. 2019;26(8):824-835. doi:10.1177/2047487318825350
6. Xie K, Bao L, Jiang X, et al. The association of metabolic syndrome components and chronic kidney disease in patients with hypertension. Lipids Health Dis. 2019;18(1):229. doi:10.1186/s12944-019-1121-5

7. Kotseva K, Wood D, De Bacquer D, et al. EUROASPIRE IV: a European Society of Cardiology survey on the lifestyle, risk factor and therapeutic management of coronary patients from 24 European countries. Eur J Prev Cardiol. 2016;23(6):636-648. doi:10.1177/ 2047487315569401

8. American Diabetes Association. 6. Glycemic targets: standards of medical care in diabetes-2019. Diabetes Care. 2019;42(Suppl 1): S61-S70. doi:10.2337/dc19-S006

9. World Health Organization. Obesity: preventing and managing the global epidemic. report of a WHO consultation. World Health Organ Tech Rep Ser. 2000;894:i-xii, 1-253.

10. Grundy SM, Cleeman JI, Daniels SR, et al. Diagnosis and management of the metabolic syndrome: an American heart association/ national heart, lung, and blood institute scientific statement. Circulation. 2005;112(17):2735-2752. doi:10.1161/ CIRCULATIONAHA.105.169404

11. American Diabetes Association. 2. Classification and diagnosis of diabetes: standards of medical care in diabetes-2019. Diabetes Care. 2019;42(Suppl 1):S13-S28. doi:10.2337/dc19-S002

12. Group SR, Wright JT Jr, Williamson JD, et al. A randomized trial of intensive versus standard blood-pressure control. $N$ Engl $J$ Med. 2015;373(22):2103-2116.

13. Unger T, Borghi C, Charchar F, et al. 2020 International Society of Hypertension global hypertension practice guidelines. J Hypertens. 2020;38(6):982-1004. doi:10.1097/HJH.0000000000002453

14. Mach F, Baigent C, Catapano AL, et al. 2019 ESC/EAS guidelines for the management of dyslipidaemias: lipid modification to reduce cardiovascular risk. Eur Heart J. 2019;40(32):2700-2709. doi:10.1093/eurheartj/ehz259

15. Collaboration NCDRF. Worldwide trends in diabetes since 1980: a pooled analysis of 751 population-based studies with 4.4 million participants. Lancet. 2016;387(10027):1513-1530.

16. Yang $\mathrm{W}, \mathrm{Lu} \mathrm{J}$, Weng J, et al. Prevalence of diabetes among men and women in China. $N$ Engl $J$ Med. 2010;362(12):1090-1101. doi:10.1056/NEJMoa0908292

17. $\mathrm{Xu} \mathrm{Y}$, Wang $\mathrm{L}, \mathrm{He} \mathrm{J}$, et al. Prevalence and control of diabetes in Chinese adults. JAMA. 2013;310(9):948-959. doi:10.1001/ jama.2013.168118

18. Wang L, Gao P, Zhang M, et al. Prevalence and ethnic pattern of diabetes and prediabetes in China in 2013. JAMA. 2017;317 (24):2515-2523. doi:10.1001/jama.2017.7596

19. Cosentino F, Grant PJ, Aboyans V, et al. 2019 ESC guidelines on diabetes, pre-diabetes, and cardiovascular diseases developed in collaboration with the EASD. Eur Heart J. 2019.
Risk Management and Healthcare Policy

\section{Publish your work in this journal}

Risk Management and Healthcare Policy is an international, peerreviewed, open access journal focusing on all aspects of public health, policy, and preventative measures to promote good health and improve morbidity and mortality in the population. The journal welcomes submitted papers covering original research, basic science, clinical \& epidemiological studies, reviews and evaluations, guidelines, expert opinion and commentary, case reports and extended reports. The manuscript management system is completely online and includes a very quick and fair peer-review system, which is all easy to use. Visit http://www.dovepress.com/testimonials.php to read real quotes from published authors. 